\title{
Nurse's Knowledge and Accuracy in Using Comfort Scale
}

\author{
Putra Agina Widyaswara Suwaryo ${ }^{1, *}$ Juliyanto $^{2}$ Endah Setianingsih $^{3}$
}

\author{
1,3 Muhammadiyah Health Science Institute of Gombong \\ ${ }^{2}$ Muhamnmadiyah Hospital of Sruweng \\ *Corresponding author. Email: ners.putra@gmail.com
}

\begin{abstract}
More than $30 \%$ of critical patients have significant pain while resting and more than $50 \%$ of patients experience significant pain during the routine care process. Pain is difficult to measure and treat in patients with reduced awareness because direct reports from patients are important in the assessment. Assessment of pain in patients with decreased consciousness can use the Comfort Scale. This research is to describe nurse's knowledge in pain assessment in patient using comfort scale in Muhammadiyah Hospital. This study uses a descriptive method with a survey approach. The sample in this study were 84 nurses taken in total sampling. Instrument in the form of a questionnaire sheet. Data was analyzed using descriptive analysis. Most of the nurses at PKU Muhammadiyah Sruweng Hospital were $\geq 30$ years old (79.8\%), female sex $(79.8 \%)$, Diploma education $(88.1 \%)$, and length of employment $\geq 5$ years $(73.8 \%)$. Knowledge of nurses in pain assessment in patients using comfort scale in Muhammadiyah Hospital was in a sufficient category (66.7\%). Pain assessment uses a comfort scale in patients in Muhammadiyah Hospital in the inappropriate category (77.4\%). Nurses' knowledge in pain assessment in sufficient categories while pain assessment uses comfort scale in inappropriate categories. Future research can be further developed by examining other factors that influence the use of comfort scale gauges.
\end{abstract}

Keywords: knowledge, pain assessment, comfort scale

\section{BACKGROUND}

Pain serves as a sensory and unpleasant emotional experience related to actual or potential or perceived tissue damage in events where damage occurs. Many critically ill adult patients experience significant pain relief during hospitalization [1]. More than 30\% of critically ill patients have significant pain while resting and more than $50 \%$ of patients experience significant pain during routine care processes, such as changes in position, endotracheal suction, and wound care [2].

Some of the factors associated with pain in critically ill individuals are: symptoms of illness such as ischemia and post-surgery, sleep disturbances and lack of sleep, immobility due to treatment devices such as tubes and tubes, anxiety and depression, communication disorders in reporting pain, fear of pain, physical disability or death, separation from family, fever, boredom from not having fun things, continuous noisy feeling due to equipment and staff, disturbance to change position in bed, and medical procedures [3], [4].

Pain is a subjective experience, so assessment is very important. There is no objective measurement tool that can provide a satisfactory assessment. Pain is also multidimensional including nociceptive perception and expression[4]. For this reason, multiple aspects of pain must also be considered, including the sensory, affective and cognitive dimensions[5]. There is no single approach that can be used to assess pain in all patients or in all situations because pain is influenced by various factors, including the use of measuring instruments, the time to assess the number of patients and the clinician itself.

Many patients in the intensive care unit (ICU), due to their illness, have left the patient unconscious or are using a ventilator breathing device, so they are unable to communicate their pain. This is a challenge for ICU nurses, because the severity of the patient's pain is often underestimated [6]. Patients in ICU are unable to communicate effectively, while the self-report method is still the "gold standard" in pain assessment according to guidelines from the International Association for The Study of Pain [7]. In the critical area of nursing many patients with sedation and intubation are unable to communicate to indicate their level of pain, either verbally or by indicating their level of pain using pain scaling aids, this makes it difficult to assess pain in this group of patients. This is why the assessment of pain in the critical nursing area is very complex[2].

Comfort Scale is a pain assessment instrument developed by Ambuel et al in 1992. The Comfort scale is used to measure the level of psychological distress in critically ill patients, children under 18 years of age and adults who are sedated and on a ventilator [8]. The comfort scale instrument has advantages, namely 
psychological indicators and behavioral indicators that are assessed from patient behavior as a sign of pain [1]. Nurses not only collaborate with other health professionals but also provide pain relief interventions, evaluate the effectiveness of interventions and act as patient advocates when interventions are ineffective [9].

Nurses' knowledge about pain and pain assessment using a comfort scale is very important. Knowledge is a very important domain for the formation of one's actions. Based on experience and research, it turns out that behavior based on knowledge will be more lasting than behavior that is not based on knowledge [10]. Nurses' knowledge of pain assessment and intervention is essential for effective and quality pain management in patient care [11]. In Indonesia, pain assessment in critical patients is still lacking even though pain that occurs in critical patients with decreased awareness can lead to stress, unpleasant feelings, and the potential to experience bad experiences during treatment, therefore pain assessment needs to be done. This fact motivated to conduct research on the description of nurses' knowledge in assessing pain in patients using a comfort scale [12]. The purpose of this study was to describe the knowledge of nurses in assessing pain in patients using a comfort scale in Muhammadiyah hospital.

\section{METHOD}

This study used 2 descriptive method with a survey approach. The sample in this study were 84 nurses who were taken by total sampling who worked in Intensive Care Unit (ICU) and Chamdani Room in Muhammadiyah Hospital of Sruweng is 84 nurse. Instrument in the form of a questionnaire sheet. The data were analysed using descriptive analysis. This research has passed the research ethics by the Research Ethics Committee of the Muhammadiyah Health Science Institute of Gombong.

\section{RESULT}

Assessment of patients with a comfort scale carried out by nurses can be seen in the table 1 and table 2 . This study used 2 descriptive method with a survey approach. Based on the table 1, it can be seen that most nurses with sufficient category knowledge were 56 respondents $(66.7 \%)$. And table 2, it can be seen that the majority of nurses with pain assessments used a comfort scale in patients with inappropriate categories of 65 respondents (77.4\%).
Table 1. Patient characteristics based on age, education and occupational status of the patient $(n=84)$

\begin{tabular}{|c|l|c|c|}
\hline & Category & $\mathrm{n}$ & $\%$ \\
\hline \multirow{2}{*}{ Age (year) } & $<30$ & 17 & 20,2 \\
\cline { 2 - 4 } & $\geqq 30$ & 67 & 79,8 \\
\hline \multirow{2}{*}{ Gender } & Female & 68 & 81 \\
\cline { 2 - 4 } & Male & 16 & 19 \\
\hline \multirow{2}{*}{$\begin{array}{c}\text { Education } \\
\text { (program) }\end{array}$} & Diploma & 74 & 88,1 \\
\cline { 2 - 4 } & Bachelor & 4 & 4,8 \\
\cline { 2 - 4 } & Ners & 6 & 7,1 \\
\hline \multirow{2}{*}{$\begin{array}{c}\text { Leng of Work } \\
\text { (year) }\end{array}$} & $<5$ & 22 & 26,2 \\
\cline { 2 - 4 } & $\geqq 5$ & 62 & 73,8 \\
\hline
\end{tabular}

Table 2. Nurse's knowledge and Accuracy of Pain Using a Comfort Scale in Patients

\begin{tabular}{|c|l|l|l|}
\hline \multirow{3}{*}{ Knowledge } & Category & n & $\%$ \\
\cline { 2 - 4 } & Bad & 2 & 2,4 \\
\cline { 2 - 4 } & Moderate & 56 & 66,7 \\
\cline { 2 - 4 } & Good & 26 & 31 \\
\hline \multirow{2}{*}{ Accuracy } & No & 65 & 77,4 \\
\cline { 2 - 4 } & Yes & 19 & 22,6 \\
\hline
\end{tabular}

\section{DISCUSSION}

The results showed that most of the nurses had sufficient knowledge (66.7\%). The least knowledge occurs in the Chamdani room. The lack of knowledge of nurses in assessing pain in patients using a comfort scale is due to the lack of update and training. In addition, it is also due to the lack of nurses attending various seminars and related training [13]. The RS Education and Training section conveyed data that training and seminars on nursing staff development programs showed that most of the training was for spiritual and personality enhancement. Meanwhile, for training and update on standard operating procedures for nursing services, especially the assessment of pain in patients using a comfort scale, it still needs to be improved, considering that this assessment requires nurses' carefulness in remembering comfort scale items [7].

The knowledge of a nurse on assessing pain in patients using a comfort scale varies depending on the level of education they have. This is related to the development of nursing science, the depth and breadth of knowledge will affect the ability of nurses to think critically in nursing actions [14]. These results are in accordance with the opinion which says that knowledge is divided into two, namely formal knowledge based on the lower level of education to a higher level and obtained from learning outcomes, and informal knowledge where this knowledge is obtained from an environment outside education, namely through mass media, media electronics, and from other people around the environment [12], [15].

Knowledge about pain assessment in patients using a comfort scale is formed by being influenced by several factors which can be classified into two parts, namely 
internal and external factors[16]. Internal factors include age and intelligence, while external factors include education, environment, experience, information, and people who are considered important. Education serves as an external factor in forming knowledge [14]. The lower a person's education, it will hinder the development of one's attitude towards acceptance, information and newly introduced values. Conversely, the higher a person's education, the easier it is to receive information and more knowledge one will have [17].

The higher the level of education, the better the absorption of information. In addition, the higher the level of education, the better the mindset will be. A good mindset will result in making a person to have better analytical skills [2]. This is in accordance with the theory which says knowledge is a very important domain for the formation of one's actions, because behavior based on knowledge and awareness will be better than behavior that is not based on knowledge because if the behavior is not based on knowledge and awareness, then the behavior will not last long [18].

The results of the questionnaire showed that most of the nurses correctly answered general questions about pain such as question number 18 about pain that can cause a person to be anxious, question number 6 about walking pain from pain receptors and question number 2 about the definition of pain. For question number 18 a number of $82(98 \%)$ nurses were able to answer correctly, question number 6 a number of $83(99 \%)$ nurses were able to answer correctly, even for question number 2 all nurses $(100 \%)$ were able to answer correctly. However, for specific questions such as question number 3 about pain that can only be known by the person experiencing it, question number 16 about the nurse who understands the most about pain and question number 17 about expression of pain control, most of the nurses answered incorrectly. For question number 3, only 15 (18\%) nurses were able to answer correctly, only a number of $11(13 \%)$ nurses were able to answer correctly, even for question number 17 only 7 (8\%) nurses were able to answer correctly right.

Pain assessment is difficult to measure and manage in unconscious patients because direct reports from patients are important in the assessment. Pain assessment in patients with decreased consciousness can use the Comfort Scale [19]. Nurses' knowledge about pain and the Comfort Scale, which are still in the adequate category, need to be improved, considering that pain management depends on systematic and accurate pain assessment [20].

The results showed that most of the nurses with pain assessments used a comfort scale in patients with inappropriate categories of 65 respondents $(77.4 \%)$. The lack of compliance with SOP for pain assessment using a comfort scale in patients can be caused by the lack of information received by nurses about standard operational procedures (SOP) and instructions for filling nursing care that are in accordance with the operational procedure [4]. Lack of adherence can also occur in the management of pediatric patients, considering that it is difficult to implement the comfort scale for pediatric patients. Nurses also have not received less socialization about SOP in accordance with applicable standards. There are many ways for institutions to strive for increased organizational performance, for example by conducting training and development, career planning, compensation, and also by assessing work performance [21].

The assessment of pain using comfort scale in patients with decreased awareness of the effects of sedation is very difficult because direct reports from patients are important in the assessment while patients cannot speak. However, pain must still be assessed and handled in a multidimensional and development outcomes framework, covering the following dimensions: physiological, sensory, affective, cognitive, behavioral, socio-cultural, and environmental [22].

Inadequate pain assessment can lead to unrecognized pain problems so that pain is not handled. Pain that is not treated optimally can adversely affect physiological functions (fluctuations in vital signs, nosocomial infections), increasing hospitalization time. comfort scale was used to assess pain in pediatric patients. in adult patients a comfort scale was used to assess pain on sedation and on a ventilator [23]

Nurses' insufficient knowledge about pain assessment causes nurses to conduct inadequate pain assessments. Knowledge is the result of sensing a certain object, knowledge or cognitive is a very high domain for the formation of one's actions (overbehavior). The higher the respondent's level of knowledge about pain assessment using a comfort scale, the better it is in conducting pain assessments using a comfort scale. Increasing the knowledge of Chamdani A room nurses about pain assessment using a comfort scale needs to be continuously improved considering that knowledge is the base of attitude, while attitudes will lead to one's actions [24]. Routinely screening, assessing, and documenting pain is an important first step in ensuring that ongoing assessment and monitoring of the patient are carried out. If the pain score is positive, there should be further pain assessment, prompt intervention, and follow-up evaluation of pain and treatment effectiveness [12].

Pain assessment is an ongoing process. The comfort scale pain observation indicator is classified into 9 categories with each category having a score of 1-5 with a total score of 9-45. If the pain is properly assessed and assessed then there will be a better chance of treating the pain in the patient properly. Pain should be measured in every complete examination and in many brief meetings. Observations showed that most of the nurses assessed alertness (95\%), calmness (96\%), and only a few 
assessed basal blood pressure (44\%) and basal heart rate (43\%). According to researchers pain should be assessed routinely and in a structured manner, but this is often not done. The inaccuracy of assessing pain using a comfort scale in patients is in line with the lack of knowledge of nurses in assessing pain in patients using a comfort scale. PKU Muhammadiyah Sruweng Hospital is expected to conduct regular training on pain assessment in patients with decreased awareness of the effects of sedation using a comfort scale.

\section{CONCLUSION}

Nurses have sufficient knowledge about assessing pain in unconscious patients using a comfort scale. some nurses have not conducted a comfort scale assessment according to standard procedures, who assess pain in children 0-3 years and pain in adults with sedation and on a ventilator. There is a need for socialization and training on pain assessment and good supervision for nurses while providing services to patients so that patients can be resolved in terms of pain problems. evaluation of making assessment formats and procedures that can be easily carried out by nurses in conducting pain assessments.

\section{ACKNOWLEDGMENTS}

In this study the researchers were still limited to only examining the knowledge and observations of nurses' actions in assessing pain in patients using a comfort scale and the results were that most nurses had sufficient knowledge and were not precise in using the comfort scale so that in future studies it is expected to compare the results of pain assessment in patients with decreased awareness using other measuring tools.

\section{REFERENCES}

[1] M. Johansson and E. Kokinsky, "The COMFORT behavioural scale and the modified FLACC scale in paediatric intensive care.," Nurs. Crit. Care, 2009, doi: 10.1111/j.1478-5153.2009.00323.x.

[2] A. J. Valkenburg, A. A. Boerlage, E. Ista, H. J. Duivenvoorden, D. Tibboel, and M. Van Dijk, "The COMFORT-Behavior scale is useful to assess pain and distress in 0- to 3-year-old children with Down syndrome," Pain, 2011, doi: 10.1016/j.pain.2011.05.001.

[3] R. Benavides, "Pain assessment," in Fundamentals of Pain Medicine, 2018.

[4] S. Ashkenazy and F. DeKeyser-Ganz, "Assessment of the reliability and validity of the Comfort Scale for adult intensive care patients," Hear. Lung, vol. 40, no. 3, pp. e44-e51, May 2011, doi: 10.1016/J.HRTLNG.2009.12.011.

[5] J. Maaskant, P. Raymakers-Janssen, E. Veldhoen, E. Ista, C. Lucas, and H. Vermeulen, "The clinimetric properties of the COMFORT scale: A systematic review," European Journal of Pain
(United Kingdom). 2016, doi: 10.1002/ejp.880.

[6] S. O. Labeau et al., "The Value of E-Learning for the Prevention of Healthcare-Associated Infections," Infect. Control Hosp. Epidemiol., vol. 37, no. 9, pp. 1052-1059, 2016, doi: 10.1017/ice.2016.107.

[7] K. Puntillo et al., "Palliative care in the ICU: Relief of pain, dyspnea, and thirst - A report from the IPAL-ICU Advisory Board," Intensive Care Medicine. 2014, doi: 10.1007/s00134-013-3153-z.

[8] C. Buratti, D. Palladino, and P. Ricciardi, "Application of a new 13-value thermal comfort scale to moderate environments," Appl. Energy, vol. 180, pp. 859-866, Oct. 2016, doi: 10.1016/J.APENERGY.2016.08.043.

[9] H. Breivik et al., "Assessment of pain," British Journal of Anaesthesia. 2008, doi: 10.1093/bja/aen103.

[10] Y. H. Leong, K. H. S. Tan, B. A. Choo, V. Y. Koh, and J. I. H. Tang, "Novel anesthetic technique for combined intracavitary and interstitial brachytherapy for cervix cancer in an outpatient setting," J. Contemp. Brachytherapy, vol. 9, no. 3, pp. 236-241, 2017, doi: 10.5114/jcb.2017.68469.

[11] J. T. Van Der Steen et al., "Tools to Assess Pain or Lack of Comfort in Dementia: A Content Analysis," J. Pain Symptom Manage., 2015, doi: 10.1016/j.jpainsymman.2015.05.015.

[12] A. De Jong et al., "Reliability, validity and clinical utility of three types of pain behavioural observation scales for young children with burns aged 0-5 years," Pain, 2010, doi: 10.1016/j.pain.2010.06.016.

[13] M. L. Czarnecki, H. N. Turner, P. M. Collins, D. Doellman, S. Wrona, and J. Reynolds, "Procedural Pain Management: A Position Statement with Clinical Practice Recommendations," Pain Manag. Nurs., 2011, doi: 10.1016/j.pmn.2011.02.003.

[14] A. Hirschmüller, H. Baur, S. Müller, P. Helwig, H. H. Dickhuth, and F. Mayer, "Clinical effectiveness of customised sport shoe orthoses for overuse injuries in runners: A randomised controlled study," Br. J. Sports Med., 2011, doi: 10.1136/bjsm.2008.055830.

[15] A. O. Akuma and S. Jordan, "Pain management in neonates: A survey of nurses and doctors," J. Adv. Nurs., 2012, doi: $10.1111 /$ j.13652648.2011.05837.x.

[16] D. Markenson, S. Woolf, I. Redlener, and M. Reilly, "Disaster medicine and public health preparedness of health professions students: A multidisciplinary assessment of knowledge, confidence, and attitudes," Disaster Med. Public Health Prep., vol. 7, no. 5, pp. 499-506, 2013, doi: 10.1017/dmp.2013.96.

[17] B. L. Ingrit, “The Application of Levine's and Kolcaba's Theories in the Nursing Care of Patients with the Third Stadium of Cervical Cancer," IJNP (Indonesian J. Nurs. Pract., vol. 3, no. 2, pp. 75-81, 2019, doi: 10.18196/ijnp.3296. 
[18] C. S. L. Chooi, A. M. White, S. G. M. Tan, K. Dowling, and A. M. Cyna, "Pain vs comfort scores after Caesarean section: A randomized trial," Br. J. Anaesth., 2013, doi: 10.1093/bja/aes517.

[19] A. A. Boerlage, E. Ista, M. De Jong, D. Tibboel, and M. Van Dijk, "The COMFORT behavior scale: Is a shorter observation period feasible?," Pediatr. Crit. Care Med., 2012, doi: 10.1097/PCC.0b013e3182192d92.

[20] M. A. A. Caljouw et al., "Measurement of pain in premature infants with a gestational age between 28 to 37 weeks: Validation of the adapted COMFORT scale," J. Neonatal Nurs., vol. 13, no. 1, pp. 13-18, Feb. 2007, doi: 10.1016/J.JNN.2006.11.007.

[21] J. Bai, L. Hsu, Y. Tang, and M. Van Dijk, "Validation of the COMFORT Behavior Scale and the FLACC Scale for Pain Assessment in Chinese Children after Cardiac Surgery," Pain Manag. Nurs., 2012, doi: 10.1016/j.pmn.2010.07.002.

[22] R. D. Andersen, T. Bernklev, A. Langius-Eklöf, B. Nakstad, and L. Jylli, "The COMFORT behavioural scale provides a useful assessment of sedation, pain and distress in toddlers undergoing minor elective surgery," Acta Paediatrica, International Journal of Paediatrics. 2015, doi: 10.1111/apa.13045.

[23] E. Ista, M. Van Dijk, D. Tibboel, and M. De Hoog, "Assessment of sedation levels in pediatric intensive care patients can be improved by using the COMFORT 'behavior' scale," Pediatr. Crit. Care Med., 2005, doi: 10.1097/01.PCC.0000149318.40279.1A.

[24] C. Rogeau, F. Beaucamp, E. Allart, W. Daveluy, and M. Rousseaux, "Pilot assessment of a comfort scale in stroke patients," J. Neurol. Sci., 2014, doi: 10.1016/j.jns.2014.01.032. 